Bangladesh J. Bot. 48(1): 25-31, 2019 (March)

\title{
ALLELIC COMPOSITION AT GLU GENES IN A COLLECTION OF SPRING WHEAT GERMPLASM
}

\author{
Munawar Shahzad, Sultan Habibullah Khan ${ }^{1}$, Muhammad SaJjad ${ }^{2}$, \\ Aziz-ur-Rehman ${ }^{3}$, Muhammad Nadeem² and Abdus Salam Khan \\ Department of Plant Breeding and Genetics, Faculty of Agriculture, \\ University of Agriculture, Faisalabad, 38000, Pakistan
}

Keywords: Gluten, Glutenin, LMW, HMW, Haplotype, Wheat, Protein, Glu genes

\begin{abstract}
For HMW-GS, a total of 16 different subunits and 30 allelic haplotypes were identified. The expression of HMW-GS ranged from 3 to 5 per genotype instead of 6 per genotype, revealing the phenomenon of gene silencing. The $2 *$ was the most frequent subunit for Glu-A1 locus and was found in $52.45 \%$ lines. Eight subunits were identified for Glu-B1 locus. Five subunit pairs i.e. $6+8,7+8,7+9,13+16$ and 17+18 were present in the germplasm. Some single subunits i.e. $6,7,8$ and 20 were also found. Subunit pair $17+18$ was the most frequent with a partial frequency of $32.17 \%$. For Glu-D1, four subunit pairs i.e. $2+12,5+10,2+11$ and 5+11 were observed. The 5+10 was the most frequent subunit for Glu-D1 and was present in $65.03 \%$ lines. The $2+12$ subunit pair was identified in $34.97 \%$ lines. For Glu3 loci 18 LMW subunits were identified. For Glu-A3, five subunits i.e. b, c, d, e and g were identified. Eight subunits i.e. b, c, d, f, g, h, i and j were identified for Glu-B3 locus. Four subunits i.e. a, b, c and 1 were identified for Glu-D3 locus.
\end{abstract}

\section{Introduction}

The property of wheat flour to be used for different products depends mainly on the wheat gluten proteins (Weegels et al. 1996). With respect to solubility, wheat proteins are grouped into four classes: albumin, globulin, prolamin and glutens. Gluten comprises $78-85 \%$ of total protein and is a large complex of mainly polymeric and monomeric proteins known as glutenins and gliadins, respectively (Gupta and MacRitchie 1991). They contribute largely towards the quality of wheat flour. The glutenins are polymeric proteins with disulphide bonds linking the individual glutenin subunits and are responsible for the unique viscoelastic properties of wheat dough. Wheat contains two types of glutenin subunits, one is low molecular weight glutenin subunits (LMW-GS) $(10-70 \mathrm{kDa})$ and the other is high molecular weight glutenin subunits (HMW-GS) (80-130 kDa) (Payne et al. 1980). Both HMW and LMW glutenin subunits play a major role in determining the viscoelastic properties of wheat flour. Although HMW-GS represents only $10 \%$ of the endosperm storage proteins (Payne et al. 1981), genetic diversity of HMW-GS is important for end use quality of wheat (Rehman et al. 2014).

Genes underpinning HMW-GS have been reported on chromosomes 1AL, 1BL and 1DL at loci Glu-A1, Glu-B1 and Glu-D1, respectively. Each of these loci contains two genes coding for $\mathrm{x}$ - and $\mathrm{y}$-type subunits (Payne 1987). A high degree of polymorphism for each locus has been observed using SDS-PAGE (Sajjad et al. 2012, Rehman et al. 2014). Many studies based on the quality scores assigned by Payne (1987) and Lukow et al. (1989) have revealed that the genetic variations at these loci play a critical role in determining dough properties (RodriguezQuijano et al. 2001).

*Author for correspondence: <msajjadpbg@gmail.com>. ${ }^{1}$ Center of Agricultural Biochemistry and Biotechnology (CABB), University of Agriculture, Faisalabad, 38000, Pakistan. ${ }^{2}$ Department of Environmental Sciences COMSATS University Islamabad, Vehari Campus, 61100, Pakistan. ${ }^{3}$ Ayub Agriculture Research Institute, Faisalabad, 38000, Pakistan. 
These variations contribute to $50-70 \%$ of the genetic variation for wheat dough properties (Lukow et al. 1989). Wheat flour is used fo making chapatti and bread. A wheat genotype could express maximum six HMW-GS but due to gene silencing most of the cultivars express only 3-5 HMW-GS (Tariq et al. 2018).

LMW-GS comprise almost 70\% of glutenins and $20-30 \%$ of the total protein (Melas et al. 1994) and 15 - 20 diverse LMW-GS proteins can be recognized in 1D and 2D gels of hexaploid wheat (Lew et al. 1992). In spite of their abundance, very little research work has been carried out on them as compared to HMW-GS, mainly because of the difficulty in their identification in SDSPAGE gels. The major hurdle in their identification was the overlapping between LMW-GS and gliadins. The present investigation shows the composition of HMW-GS and LMW-GS in a collection of 116 spring wheat landraces, breeding lines and cultivars.

\section{Materials and Methods}

A collection of 116 spring wheat landraces, breeding lines and varieties was included in the study. Storage proteins were extracted from single seed following sequential procedure developed by Singh et al. (1991). The extracted proteins were run on SDS-PAGE using the protocol standardized by Sambrook and Russell (2001). Allelic variation for HMW-GS at Glu-1 loci was recorded according to Payne and Lawrence (1983). Quality scores were calculated according to Payne (1987) by adding together the scores of individual sub-units. Allelic variation for LMWGS was determined according to Jackson et al. (1996). Allelic designation of each subunit was adopted from MacGenes (McIntosh et al. 2008). The genetic diversity at each locus was calculated using Nei's index (Nei 1973) using formula, $\mathrm{H}=1-\sum P i^{2}$ where $\mathrm{H}$ and Pi denote the genetic variation and the frequency of alleles, respectively.

\section{Results and Discussion}

Considerable diversity of HMW-GS was found in the germplasm. A total of 16 different subunits and 30 allelic haplotypes were identified. All the common HMW glutenin subunits were found in the germplasm. The expression of HMW-GS ranged from 3 to 5 per genotype instead of 6 per genotype, revealing the phenomenon of gene silencing. Three subunits i.e. 1, $2^{*}$ and Null were identified for Glu-A1 locus. The $2 *$ was the most frequent subunit for Glu-A1 locus and was found in $52.45 \%$ of the lines (Fig. 1). The subunit 1 was found in $41.26 \%$ genotypes while null was present in $6.99 \%$ genotypes. Eight subunits were identified for Glu-B1 locus. Five subunit pairs i.e. $6+8,7+8,7+9,13+16$ and $17+18$ were present in the germplasm. Some single subunits i.e. $6,7,8$ and 20 were also found. Subunit pair $17+18$ was the most frequent with a partial frequency of 32.17. It was followed by subunit pair $7+9$ with a partial frequency of 28.67 . Subunit pair $7+8$ also had relatively high proportion with a partial frequency of $15.38 \%$. Other subunits were not as frequent as the ones explained above (Fig. 1). For Glu-D1, four subunit pairs i.e. $2+$ $12,5+10,2+11$ and $5+11$ were observed. The $5+10$ was the most frequent subunit for Glu-D1 and was present in $65.03 \%$ lines. $2+12$ was identified in $34.97 \%$ lines. The other two subunit pairs had very low frequencies (Fig. 1). A marked difference was observed for the frequencies of different subunits between the modern cultivars (Pakistani and CIMMYT) and pre-green revolution germplasm (LLR). The subunits Null and 1 for Glu-A1, 13+16 and 20 for Glu-B1 and 2+12 for Glu-D1 were more frequent among the LLR group genotypes but these subunits were less frequent in modern cultivars.

According to the number of alleles expressed at Glu-A, Glu-B and Glu-D loci a total of 108 haplotypes were expected but anthropogenic selection reduced the observed number of haplotype to about 30 (Table 1). Deviation from Hardy-Weinberg's equilibrium was also evident from 
unequal frequencies of haplotype in selected germplasm. The most frequent haplotypes were " 1 , $17+18,5+10$ " and " $2 *, 17+18,5+10$ ". However, 25 haplotypes had frequency less than 5 (Table 1)

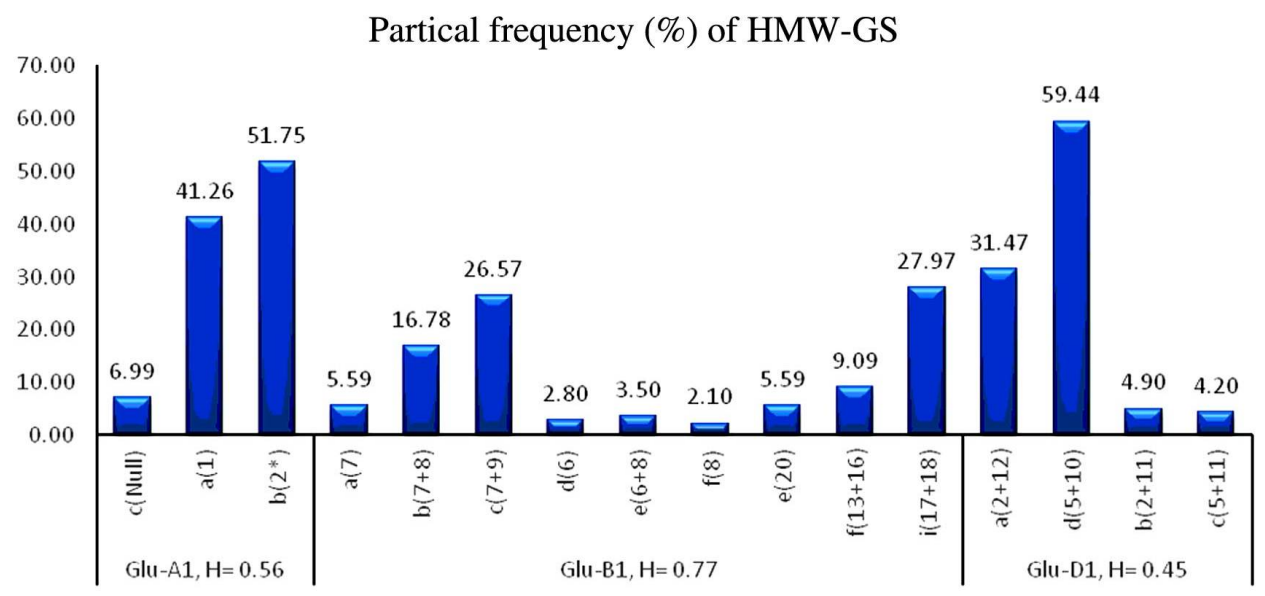

Fig. 1. Partial frequencies of HMW-glutenin subunits.

Total 16 Glu-1 alleles were observed (Fig. 1). A similar extent of allelic diversity at Glu-1 loci has been reported previously (Liu et al. 2007 and Sajjad et al. 2012). Jun et al. (2012) identified 26 HMW glutenin subunits with 83 different combinations in a population of 1942 advanced lines and cultivars from eight different wheat-growing zones of China. The genotypes studied had a high frequency of high quality subunits i.e. $5+10,17+18$ and $2 *$. This is probably because the material mainly consisted of approved Pakistani varieties and advanced lines. In Pakistan, chapatti quality is an important criterion for selection of the wheat lines. The frequency of these high quality subunits is higher than that reported by Jun et al. (2012) in 1942 Chinese cultivars and Sajjad et al. (2012) in Pakistani and CIMMYT lines. A considerable variation in the frequency of subunits was observed between the pre-green revolution and post green-revolution germplasm. The landraces had a high frequency of null and 1 subunits for Glu-A1, subunit 20 for Glu-B1 and subunit pair 2+12 for Glu-D1. This distribution was very much like the one found by Jun et al. (2012) in Chinese cultivars and by Rehman et al. (2014) in Pakistani landraces. The phenomenon of higher allelic diversity in landraces than those in modern varieties has also been observed at 44 SSR loci in Pakistani wheat collection (Sajjad et al. 2018). Besides landraces, Dgenome synthetic wheat lines also exhibited higher allelic diversity Glu-1 loci than common Pakistani wheat varieties (Tariq et al. 2018). The accessions with high quality HMW glutenin subunits also performed better in terms of chapatti quality and NIR gluten. The varieties Lasani, Sehar, LU26s, Shafaq and several others had the best combination of HMW-GS. These varieties also had very good scores of gluten, chapatti and bread quality (Rehman et al. 2014).

Eighteen LMW subunits were identified for Glu3 loci (Fig. 2). All the common LMW glutenin subunits were found in the germplasm. Every line had 3 - 5 subunits. For Glu-A3, five subunits i.e. b, c, d, e and $\mathrm{g}$ were identified. Glu-A3c had the highest frequency of 52.45\%, followed by Glu-A3b (20.98\%) and Glu-A3d (14.75\%). Other subunits had very low frequencies. Eight subunits i.e. b, c, d, f, g, h, i and j were identified for Glu-B3 locus. Glu-B3j (26.57\%), Glu-B3h (22.38\%), Glu-B3b (15.38\%), Glu-B3i (13.29\%) and Glu-B3g (11.89\%) had the higher 
Table 1. Observed haplotypes at Glu1 genes in selected germplasm.

\begin{tabular}{|c|c|c|c|c|c|c|}
\hline $\begin{array}{l}\text { Sr. } \\
\text { no. }\end{array}$ & GluA1 & GluB1 & GluD1 & Frequency & & $\begin{array}{l}\text { Glu } \\
\text { score }\end{array}$ \\
\hline 1 & 1 & $7+8$ & $5+10$ & 1 & Faisalabad-08 & 10 \\
\hline 2 & 1 & $13+16$ & $5+10$ & 7 & T11, T12, ZA-77, PASBAN 90, SA-42, SA-75, WH542 & 10 \\
\hline 3 & 1 & $17+18$ & $5+10$ & 18 & $\begin{array}{l}\text { T25, 8A, 9D, YECORA, KIRAN-95, MEHRAN-89, } \\
\text { SULEMAN-96, ZARGOON-79, CHAKWAL-97, CHENAB- } \\
\text { 79, FAISALABAD-85, LYP-73, MANTHAR, PARI-73, } \\
\text { PASINA-90, BOBWHITE'S', G109, G110, }\end{array}$ & 10 \\
\hline 4 & $2 *$ & $7+8$ & $5+10$ & 8 & $\begin{array}{l}\text { T24, SEHER-06, CHAKWAL-50, JAUHAR-78, SH-2002, } \\
\text { OASIS, SAAR, G113 }\end{array}$ & 10 \\
\hline 5 & $2^{*}$ & $13+16$ & $5+10$ & 3 & SINDH-81, Naeem-82, PRL'S'/PVN & 10 \\
\hline 6 & $2 *$ & $17+18$ & $5+10$ & 17 & $\begin{array}{l}\text { PARWAZ-94, SHAFAQ-06, AARI-10, K|HIRMAN, } \\
\text { SOGHAT-90, ZARDANA 89, ZARLASHTA 99 } \\
\text { PUNJAB-76, PUNJAB-85, PUNJAB-96, V-90A332, PBW } \\
\text { 450, FRET-2, KARIEGA, G107, G112, ZAMINDAR-80 }\end{array}$ & 10 \\
\hline 7 & 1 & $7+9$ & $5+10$ & 3 & ABADGAR-93, KOHSAR95. PAK81 & 9 \\
\hline 8 & $2 *$ & $7+9$ & $5+10$ & 8 & $\begin{array}{l}\text { T19, LASANI-08, ANMOLE91, SALEEM2000, } \\
\text { PIRSABAK-04, LU26, WATAN, NACOZARI } 6\end{array}$ & 9 \\
\hline 9 & $2 *$ & $7+8$ & $2+12$ & 3 & C-258, PIRSABAK-05, ZARDANA89 & 8 \\
\hline 10 & $2 *$ & $17+18$ & $2+12$ & 4 & INQLAB-91, SARSABZ, BLUE SILVER, MEXIPAK65 & 8 \\
\hline 11 & $2 *$ & 7 & $5+10$ & 3 & BAYA'S', FRET-1, G116 & 8 \\
\hline 12 & 1 & $13+16$ & $2+12$ & 1 & $\mathrm{~T} 16$ & 8 \\
\hline 13 & 1 & $17+18$ & $2+12$ & 4 & T23, C-250, MIRAJ-08, CHENAB-70 & 8 \\
\hline 14 & 1 & 7 & $5+10$ & 2 & BACANORA, BYRSA-87 & 8 \\
\hline 15 & 1 & 20 & $5+10$ & 2 & $\mathrm{C} 273, \mathrm{C} 271$ & 8 \\
\hline 16 & 1 & 20 & $2+12$ & 2 & BHITTAI, KAKATSI & 6 \\
\hline 17 & 1 & $7+8$ & $2+12$ & 7 & $\begin{array}{l}\text { T13, T14, T17, CHAKWAL-86, KOHISTAN97, CHAM-6, } \\
\text { HARTOG }\end{array}$ & 8 \\
\hline 18 & 1 & $7+9$ & $2+12$ & 2 & Fsd-83, IQBAL-2000 & 7 \\
\hline 19 & 1 & $6+8$ & $5+10$ & 1 & T.J-83 & 8 \\
\hline 20 & $2^{*}$ & $7+9$ & $2+12$ & 3 & GA-2002, BHAKKAR2000, G107 & 7 \\
\hline 21 & $2^{*}$ & $13+16$ & $2+12$ & 4 & T20, FAREED-6, MARVI2000, V-03007 & 8 \\
\hline 22 & $2 *$ & 20 & $2+12$ & 1 & C-518 & 6 \\
\hline 23 & $2^{*}$ & $6+8$ & $2+12$ & 3 & SASSI, CHAM-4, PFAU/WEAVER & 6 \\
\hline 24 & 0 & $13+16$ & $5+10$ & 1 & $\mathrm{~T} 22$ & 8 \\
\hline 25 & 0 & $6+8$ & $5+10$ & 1 & $\mathrm{~T} 15$ & 6 \\
\hline 26 & 0 & $17+18$ & $2+12$ & 1 & PUNJAB-96 & 6 \\
\hline 27 & 0 & $7+8$ & $5+10$ & 1 & $\mathrm{~T} 18$ & 8 \\
\hline 28 & 0 & $7+8$ & $2+12$ & 1 & $\mathrm{C}-245$ & 6 \\
\hline 29 & 0 & 20 & $2+12$ & 3 & $\mathrm{C}-217, \mathrm{C}-228, \mathrm{C}-591$ & 4 \\
\hline 30 & 0 & 7 & $2+12$ & 1 & LOCAL TALL & 4 \\
\hline
\end{tabular}


frequencies for the locus, while, others had very low frequencies (Fig. 2). Four subunits i.e. a, b, c and 1 were identified for Glu-D3 locus. The allele $b$ was the most frequent subunit for Glu-D3 locus and was found in $51.75 \%$ of the lines, followed by Glu-D3a which was present in $36.36 \%$ lines. The other two subunits had very low frequencies (Fig. 2).

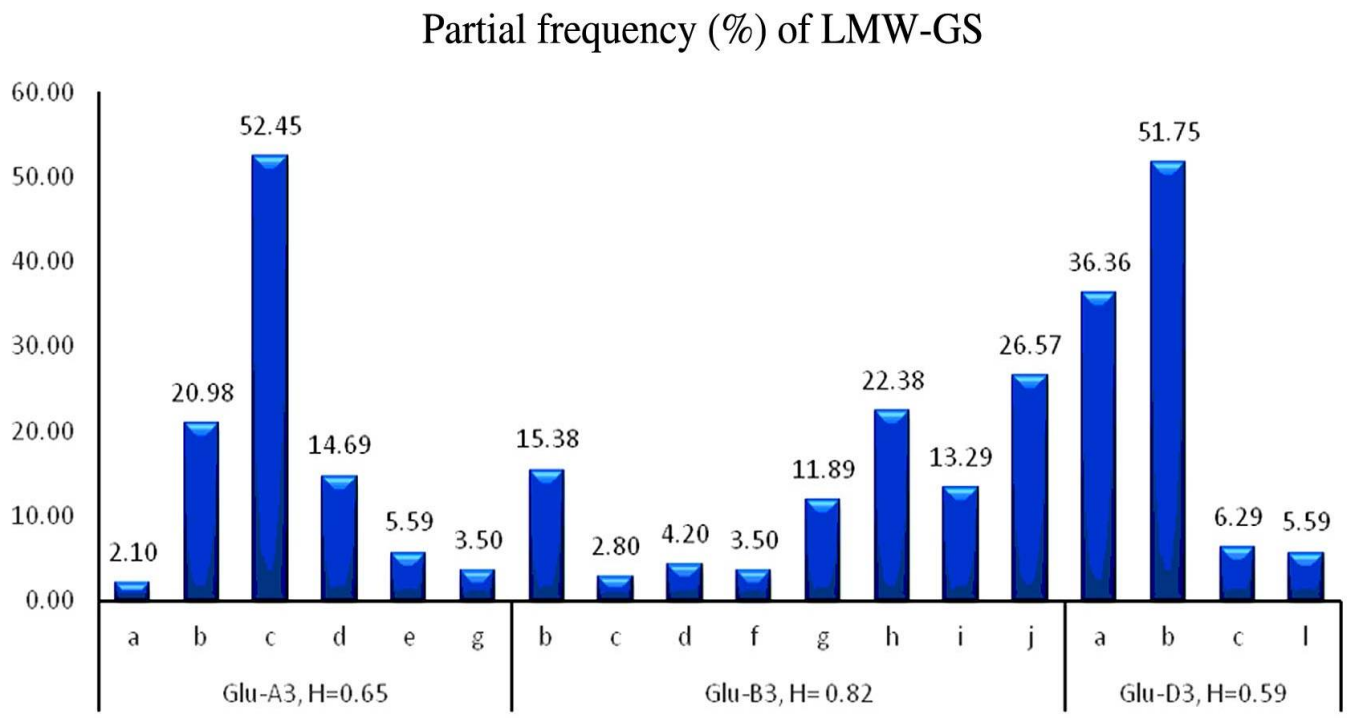

Fig. 2. Partial frequencies of LMW-glutenin subunits in 92 spring wheat genotypes.

HMW-GS are important in determining wheat dough elasticity, and LMW-GS are related to dough extensibility and gluten strength (Cornish et al. 2001, Ma et al. 2005). Si et al. (2012) found 10 Glu-B3 subunits using molecular marker approach which is the best suited approach for the identification of LMW glutenin subunits. The frequency pattern reported was 'i' ' $a$ ' $>$ 'd'> 'g'> 'f'> 'b'> 'e'> 'c'> 'j'> 'h'. Subunit b had a more pronounced effect on gluten strength. Rehman et al. (2014) also reported the presence of superior quality subunits for both high and low molecular weight glutenin subunits. The most frequent LMW-GS were Glu-A3c, Glu-B3j, and Glu-D3b. These results are in line with the ones reported in the present study. The identification of LMW-GS using SDS-PAGE is a difficult job because of high number of candidate subunits and their similar molecular weight. Some better approaches e.g. MLDi-TOF MS, 2D-electrophoresis and molecular markers are recommended for this purpose. The use of allele specific molecular markers is the best approach for this purpose. It is possible to improve the results of the present study regarding LMW-GS by using any of the above stated techniques.

\section{References}

Branlard G, Autran JC and Monneveux P 1989. High molecular weight glutenin subuinit in durum wheat (T. durum). Theor. Appl. Genet. 78: 353-358.

Cornish GB, Bekes F, Allena HM and Martin DJ 2001. Flour proteins linked to quality traits in an Australian doubled haploid wheat population. Aus. J. Agric. Res. 52: 1339-1348.

Gupta RB, and MacRitchie F 1991. A rapid one-step one-dimensional SDS-PAGE procedure for analysis of subunit composition of glutenin in wheat. J. Cereal Sci. 14: 105-109. 
Halverson J and Zeleny L 1988. Criteria of wheat quality. In: Wheat Chemistry \& Tech. (Y. Pomeranz, ed.). American Association of Cereal Chemist. Inc., St. Paul, MN. pp 15-46.

Jackson EA, Morel MH, Sontag-Strohm T, Branlard G, Metakovsky EV and Redaelli R 1996. Proposal for combining the classification systems of alleles of Gli-1 and Glu-3 loci in bread wheat (Triticum aestivum L.). J. Genet. Breed. 50: 321-336.

Jun Ji, Guo X, Cui F, Liu D, Sun J, Zhang W, Zhang A and Li J 2012. Variations in high-molecular-weight glutenin subunits in the main wheat growing zones in China. Aus. J. Crop Sci. 6(5): 912-917

Lew EJL, Kuzmicky DD and Kasarda DD 1992. Characterization of low molecular weight glutenin subunits by reversed-phase high-performance liquid chromatography, sodium dodecyl sulfate-polyacrylamide gel elctrophoresis, and N-terminal amino acid sequencing. Cereal Chem. 69: 508-515.

Liu J, Liu L, Hou N, Zhang A and Liu C 2007. Genetic diversity of wheat genepool of recurrent selection assessed by microsatellite markers and morphological traits. Euphytica 155: 249-258.

Lukow OM, Payne PI and Tkachuk R 1989. The HMW glutenin subunit composition of Canadian wheat cultivars and their association with bread-making quality. J. Sci. Agric. 46: 451-460.

Ma W, Appels R, Bekes F, Larroque O, Morell MK and Gale KR 2005. Genetic characterization of dough rheological properties in a wheat doubled haploid population: additive genetic effects and epistatic interactions. Theor. Appl. Genet. 111: 410-422.

McIntosh RA, Yamazaki Y, Dubcovsky J, Rogers J, Morris C., Somers DJ, Appels R, Devos KM 2008. Catalogue of gene symbols for wheat. MacGene. https://shigen.nig.ac.jp/wheat/komugi/genes/download.jsp

Melas V, Morel MH, Autran JC and Feillet P 1994. Simple and rapid method for purifying low molecular weight subunits of glutenin from wheat. Cereal Chem. 71(3): 234-237.

Nei M 1973. Analysis of gene diversity in subdivided populations. Proceed. National Acad. Sci. USA., 70: 3321-3323.

Payne PI 1987. Genetics of wheat storage protein and the effect of allelic variation on breadmaking quality. Ann. Rev. Plant Physiol. 38:141-153.

Payne PI and Lawrence GJ 1983. Catalogue of alleles for the complex gene loci, Glu-A1, Glu-B1, and GluD1 which code for the high molecular weight subunits of glutenin in hexaploid wheat. Cereal Res. Commun. 11: 29-35.

Payne PI, Law CN and Mudd EE 1980. Control of homoelogous group 1 chromosomes of the highmolecular-weight subunits of glutenin, a major protein of wheat endosperm. Theor. Appl. Genet. 58:113-120.

Payne PI, Holt LM and Law CN 1981. Structural and genetic studies on the high-molecular-weight subunits of wheat glutenin. I. Allelic variation in subunits amongst varieties of wheat (Triticum aestivum). Theor. Appl. Genet. 60: 229-236.

Rehman A, Sajjad M, Khan SH, Peña Bautista RJ and Khan NI 2014. Lower tendency of allelic variation of Glu genes and absence of 1BL-1RS translocation in modern Pakistani wheats. Cereal Res. Commun. 42(1): 139-150.

Rodriguez-Quijano M, Nieto-Taladriz MT, Gomez M, Vazquez JF and Carrillo JM 2001. Quality influence comparison of some $\mathrm{x}$ - and y-type HMW-glutenin subunits. Wheat in a Global Environment. pp. 189194

Sajjad M, Khan SH and Shahzad M 2018. Patterns of allelic diversity in spring wheat populations by SSRmarker. Cytol. Genet. 52: 155-160.

Sajjad M, Khan SH, Maqbool R, Ather A and Iqbal N 2012. Selection of Pakistani and CIMMYT wheat lines for better grain yield and quality. Int. J. Agric. Biol. 14: 645-649.

Sambrook J and Russell DW 2001. Molecular cloning: A Laboratory Manual. Cold Spring Harbor Laboratory Press, New York, USA.

Si HQ, Gao Y, Liu FF, Li ZX and Ma CX 2012. Distribution of low-molecular-weight glutenin subunit GluB3 alleles in mini core collections of Chinese wheat germplasms. Aus. J. Crop Sci. 6: 1390-1394 
Singh NK and Shepherd KW 1988. The structure and genetic control of a new class of disulphide-linked proteins in wheat endosperm. Theor. Appl. Genet. 71: 79-92.

Singh NK, Shepherd KW and Cornish GB 1991. A simplified SDS-PAGE procedure for separating LMW subunits of glutenin. J. Cereal Sci. 14: 203-208.

Tariq MJ, Shah MKN, Hassan MU, Sajjad M, Jamil M, Ali N and Kazi AM 2018. Prevelance of higher glutenin variation in synthetic wheat germplasm. The J. Animal Plant Sci. 28(2): 568-575.

Weegels PL, van de Pijpekamp M, Graveland A, Hamer RJ and Schofield JD 1996. Depolymerisation and repolymerisation of wheat glutenin during dough processing. Relationships between glutenin macropolymer content and quality parameters. J. Cereal Sci. 23:103-111.

(Manuscript received on 15 February, 2018; revised on 16 April, 2018) 